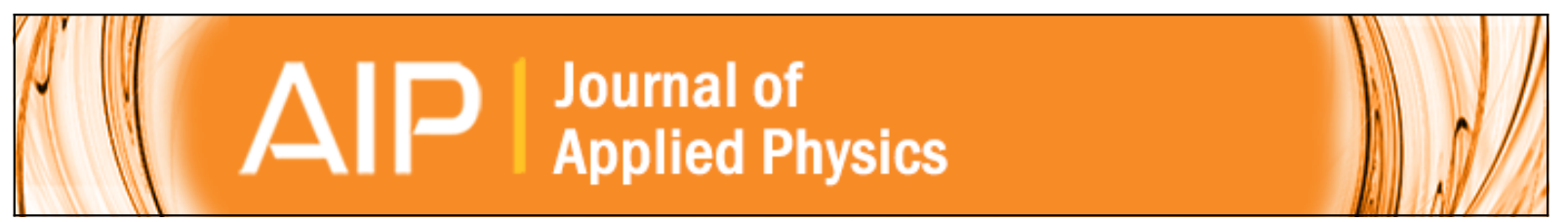

\title{
Epitaxy of polar semiconductor Co304 (110): Growth, structure, and characterization
}

Kristy J. Kormondy, Agham B. Posadas, Alexander Slepko, Ajit Dhamdhere, David J. Smith, Khadijih N. Mitchell, Travis I. Willett-Gies, Stefan Zollner, Luke G. Marshall, Jianshi Zhou, and Alexander A. Demkov

Citation: Journal of Applied Physics 115, 243708 (2014); doi: 10.1063/1.4885048

View online: http://dx.doi.org/10.1063/1.4885048

View Table of Contents: http://scitation.aip.org/content/aip/journal/jap/115/24?ver=pdfcov

Published by the AIP Publishing

\section{Articles you may be interested in}

Magnetic and structural properties of $\mathrm{BiFeO} 3$ thin films grown epitaxially on $\mathrm{SrTiO} / \mathrm{Si}$ substrates

J. Appl. Phys. 113, 17D919 (2013); 10.1063/1.4796150

$\mathrm{N}$-type conductivity and properties of carbon-doped $\ln \mathrm{N}(0001)$ films grown by molecular beam epitaxy J. Appl. Phys. 113, 033501 (2013); 10.1063/1.4775736

Role of sapphire nitridation temperature on GaN growth by plasma assisted molecular beam epitaxy: Part I. Impact of the nitridation chemistry on material characteristics

J. Appl. Phys. 91, 2499 (2002); 10.1063/1.1435834

Characterization of strained $\mathrm{Si} / \mathrm{Si}$ 1y $\mathrm{C}$ y structures prepared by molecular beam epitaxy

J. Vac. Sci. Technol. B 16, 1621 (1998); 10.1116/1.589846

In situ photoemission and reflectance anisotropy spectroscopy studies of CdS grown on $\operatorname{lnP}(001)$

J. Vac. Sci. Technol. B 15, 1260 (1997); 10.1116/1.589447

\section{AlP $\left.\right|_{\text {Applied Physics }} ^{\text {Journal of }}$}

Journal of Applied Physics is pleased to announce André Anders as its new Editor-in-Chief 


\title{
Epitaxy of polar semiconductor $\mathrm{Co}_{3} \mathrm{O}_{4}(110)$ : Growth, structure, and characterization
}

\author{
Kristy J. Kormondy, ${ }^{1}$ Agham B. Posadas, ${ }^{1}$ Alexander Slepko, ${ }^{1, a)}$ Ajit Dhamdhere, ${ }^{2}$ \\ David J. Smith, ${ }^{2}$ Khadijih N. Mitchell, ${ }^{3}$ Travis I. Willett-Gies, ${ }^{3}$ Stefan Zollner, ${ }^{3}$ \\ Luke G. Marshall, ${ }^{4}$ Jianshi Zhou, ${ }^{4}$ and Alexander A. Demkov ${ }^{1, b)}$ \\ ${ }^{1}$ Department of Physics, University of Texas at Austin, Austin, Texas 78712, USA \\ ${ }^{2}$ Department of Physics, Arizona State University, Tempe, Arizona 85287, USA \\ ${ }^{3}$ Department of Physics, New Mexico State University, Las Cruces, New Mexico 88003, USA \\ ${ }^{4}$ Materials Science and Engineering Program/Mechanical Engineering, University of Texas at Austin, \\ Austin, Texas 78712, USA
}

(Received 19 April 2014; accepted 13 June 2014; published online 30 June 2014)

The (110) plane of $\mathrm{Co}_{3} \mathrm{O}_{4}$ spinel exhibits significantly higher rates of carbon monoxide conversion due to the presence of active $\mathrm{Co}^{3+}$ species at the surface. However, experimental studies of $\mathrm{Co}_{3} \mathrm{O}_{4}$ (110) surfaces and interfaces have been limited by the difficulties in growing high-quality films. We report thin (10-250 $\mathrm{A}$ ) $\mathrm{Co}_{3} \mathrm{O}_{4}$ films grown by molecular beam epitaxy in the polar (110) direction on $\mathrm{MgAl}_{2} \mathrm{O}_{4}$ substrates. Reflection high-energy electron diffraction, atomic force microscopy, $\mathrm{x}$-ray diffraction, and transmission electron microscopy measurements attest to the high quality of the as-grown films. Furthermore, we investigate the electronic structure of this material by core level and valence band x-ray photoelectron spectroscopy, and first-principles density functional theory calculations. Ellipsometry reveals a direct band gap of $0.75 \mathrm{eV}$ and other interband transitions at higher energies. A valence band offset of $3.2 \mathrm{eV}$ is measured for the $\mathrm{Co}_{3} \mathrm{O}_{4} / \mathrm{MgAl}_{2} \mathrm{O}_{4}$ heterostructure. Magnetic measurements show the signature of antiferromagnetic ordering at $49 \mathrm{~K}$. FTIR ellipsometry finds three infrared-active phonons between 300 and $700 \mathrm{~cm}^{-1}$. (C) 2014 AIP Publishing LLC.

[http://dx.doi.org/10.1063/1.4885048]

\section{INTRODUCTION}

Complex oxides of cobalt find applications in gas sensing, ${ }^{1,2}$ spintronics, ${ }^{3-6}$ batteries, ${ }^{2,4}$ and catalysis, ${ }^{7-14}$ most notably for oxidation of carbon monoxide $(\mathrm{CO})^{9,10}$ and water. ${ }^{11-14}$ At room temperature, the most stable form of cobalt oxide is $\mathrm{Co}_{3} \mathrm{O}_{4}$, a semiconductor with a modest band gap of less than $1.6 \mathrm{eV}$, as compared to the $2.4 \mathrm{eV}$ gap of charge-transfer insulator $\mathrm{CoO} .^{15-20}$

$\mathrm{Co}_{3} \mathrm{O}_{4}$ assumes the cubic $F d 3 \mathrm{~m}$ spinel-type phase, shown in Fig. 1. Cobalt spinels have a history of use as gemstones, and their high stability makes them well-suited for the decorating of ceramics (cobalt-containing spinels, in particular, are responsible for the striking "cobalt blue" pigment). ${ }^{21,22}$ In $\mathrm{Co}_{3} \mathrm{O}_{4}$, vertex-sharing tetrahedral $\mathrm{Co}^{2+}$ ions carry a magnetic moment, while the nonmagnetic $\mathrm{Co}^{3+}$ ions occupy the edge-sharing octahedral sites. $\mathrm{Co}_{3} \mathrm{O}_{4}$ undergoes an antiferromagnetic phase transition below $\sim 40 \mathrm{~K} .^{23-26}$

Studies of crystalline thin film surfaces and interfaces of $\mathrm{Co}_{3} \mathrm{O}_{4}$ spinel could provide insight into its basic properties and catalytic behavior. ${ }^{2,7-13}$ of particular interest is the (110) plane that exhibits significantly higher reaction rates due to the presence of active $\mathrm{Co}^{3+}$ species at the surface. ${ }^{10}$ Though epitaxially grown films offer a natural way to achieve high crystallinity, epitaxy of $\mathrm{Co}_{3} \mathrm{O}_{4}$ is complicated by the fact that all low-index planes are polar. As shown in Fig. 2, the (110) direction of $\mathrm{Co}_{3} \mathrm{O}_{4}$ contains two types of

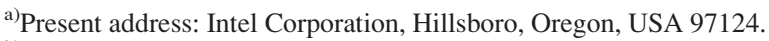

b)demkov@physics.utexas.edu
}

alternating planes: the most stable type-A plane is comprised of units of $\mathrm{Co}_{2}^{2+} \mathrm{Co}_{2}^{3+} \mathrm{O}_{4}$ with a formal charge of +2 , while the type-B planes include $\mathrm{Co}_{2}^{3+} \mathrm{O}_{4}$, resulting in a charge of -2 per surface unit cell. This polarity further motivates study of polar $\mathrm{Co}_{3} \mathrm{O}_{4}$, as polar oxides are of prominent interest due to their increased surface reactivity as compared to the bulk ${ }^{27,28}$ and as a mechanism for the formation of the two dimensional electron gas (2DEG). ${ }^{29,30}$

$\mathrm{Co}_{3} \mathrm{O}_{4}$ films have been grown by post-oxidation, ${ }^{17,31}$ atomic layer deposition (ALD), ${ }^{32-34}$ chemical vapor deposition (CVD), ${ }^{35-38}$ pulsed laser deposition (PLD), ${ }^{18,39}$ and molecular beam epitaxy (MBE). ${ }^{40-42} \mathrm{~A}$ number of substrates, including $\mathrm{MgO},{ }^{18,34,36,38,39} \mathrm{SrTiO}_{3},{ }^{18,34,38,39} \mathrm{MgAl}_{2} \mathrm{O}_{4},{ }^{36,41,42}$ $\mathrm{Al}_{2} \mathrm{O}_{3},{ }^{18,40} \mathrm{LaAlO}_{3},{ }^{39}$ Yttria-stabilized zirconia, ${ }^{39} \mathrm{SiO}_{2} /$ $\mathrm{Si}^{32,33}$ and iridium ${ }^{31}$ have been studied for the growth of crystalline $\mathrm{Co}_{3} \mathrm{O}_{4}$ films. Among these substrates, spinel $\mathrm{MgAl}_{2} \mathrm{O}_{4}$ (110) is an ideal substrate choice not only due to its small lattice mismatch with $\mathrm{Co}_{3} \mathrm{O}_{4}$ (less than $0.05 \%$ ) but also due to the fact that it is the only substrate thus far on which $\mathrm{Co}_{3} \mathrm{O}_{4}$ preferentially grows (110)-oriented. ${ }^{41,42} \mathrm{MBE}$ growth offers several advantages including precise control over flux and in situ analysis, but reports by Vaz et al. have suggested that extensive post-growth ex situ annealing is required. ${ }^{41,42}$

In this work, we report on thin MBE-grown $\mathrm{Co}_{3} \mathrm{O}_{4}$ films on $\mathrm{MgAl}_{2} \mathrm{O}_{4}$ substrates. We probe the structure of these asgrown highly crystalline (110)-oriented films by reflection high-energy electron diffraction (RHEED), atomic force microscopy (AFM), x-ray diffraction (XRD), and transmission electron microscopy (TEM). The film surface roughens at intermediate thickness, but slowly smoothens as growth 


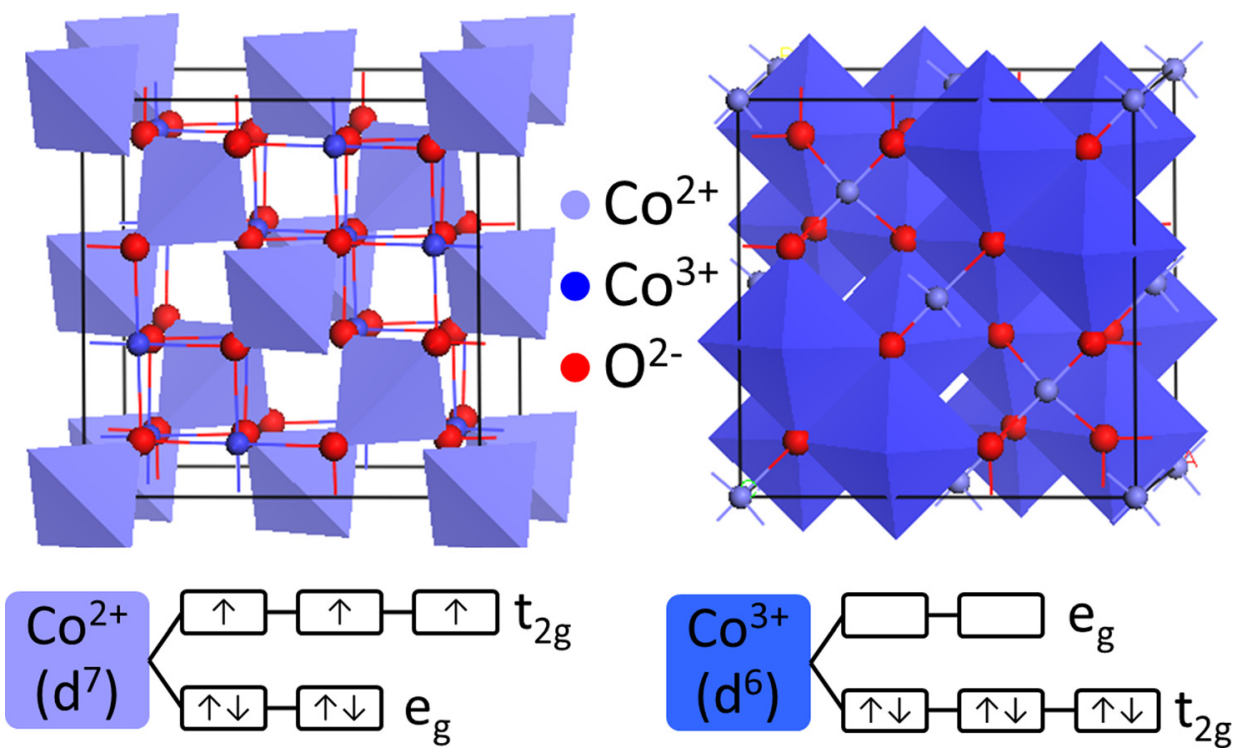

FIG. 1. At room temperature, $\mathrm{Co}_{3} \mathrm{O}_{4}$ assumes the normal spinel structure. Based on the crystal field splitting, the $\mathrm{Co}^{2+}$ ions (tetrahedral, light blue) carry magnetic moment, while the $\mathrm{Co}^{3+}$ (octahedral, dark blue) ions are nonmagnetic.

continues, returning to an RMS surface roughness of $\sim 1 \AA$. A valence band offset (VBO) of $3.2 \mathrm{eV}$ is measured for the heterostructure by $\mathrm{x}$-ray photoelectron spectroscopy (XPS). First-principles density functional theory (DFT) calculations optimized to match the shape of the XPS valence band yield a band gap of $0.6 \mathrm{eV}$ for $\mathrm{Co}_{3} \mathrm{O}_{4}$. Ellipsometry reveals a direct band gap of $0.75 \mathrm{eV}$ and other interband transitions at higher energies. FTIR ellipsometry finds three infrared-active phonons between 300 and $700 \mathrm{~cm}^{-1}$. Superconducting quantum interference device (SQUID) magnetometry measurements show the signature of antiferromagnetic ordering at an enhanced Néel temperature of $49 \mathrm{~K}$.

\section{EXPERIMENTAL DETAILS}

$\mathrm{MgAl}_{2} \mathrm{O}_{4}$ substrates of dimension $5 \mathrm{~mm} \times 5 \mathrm{~mm}$ $\times 0.5 \mathrm{~mm}$ were degreased in acetone, isopropanol, deionized water, and UV ozone. Substrates were glued with silver paste to a sample holder to ensure good thermal contact. The samples were then introduced into a customized DCA $600 \mathrm{MBE}$ system with a base pressure of $3 \times 10^{-10}$ Torr. All substrates were outgassed in the chamber at $700{ }^{\circ} \mathrm{C}$ for $30 \mathrm{~min}$ before lowering the substrate temperature to $500^{\circ} \mathrm{C}$ for growth. The substrate temperature is measured by a thermocouple in close proximity to the substrate heater; the thermocouple is calibrated using a pyrometer measurement of a silicon substrate.

The electron-beam evaporated Co flux was calibrated to a deposition rate of $3-4 \AA / \mathrm{min}$ by use of a quartz crystal microbalance. Atomic oxygen was then introduced by means of an RF plasma source at a power of $250 \mathrm{~W}$ with an oxygen background pressure of $1 \times 10^{-5}$ Torr. After growth, the main shutter was closed, and the samples were cooled down in the presence of oxygen. The presence of the film affects the visual appearance of the sample, adding a brown tint as compared to the transparent substrate. This is consistent with the smaller band gap of $\mathrm{Co}_{3} \mathrm{O}_{4}$ as compared to that of the $\mathrm{MgAl}_{2} \mathrm{O}_{4}$ substrate. ${ }^{18,43}$ For ellipsometry measurements, a $\mathrm{Co}_{3} \mathrm{O}_{4}$ film was deposited on a large 2-in.-diameter $\mathrm{MgAl}_{2} \mathrm{O}_{4}$ substrate to eliminate artifacts due to the size of the sample. The unpolished side of this wafer was coated with $\mathrm{Nb}$ metal rather than silver paste before following the steps outlined above.

The samples were monitored during growth by in situ RHEED, and then transferred in situ to the XPS analysis

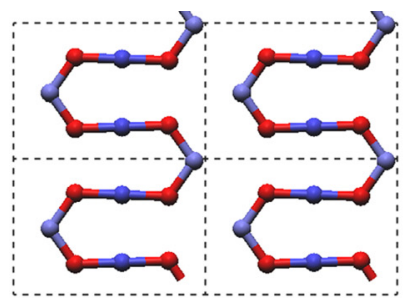

Type A (+2)

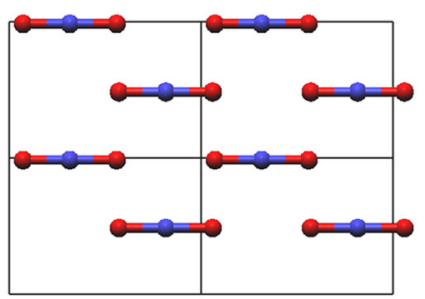

Type B (-2)

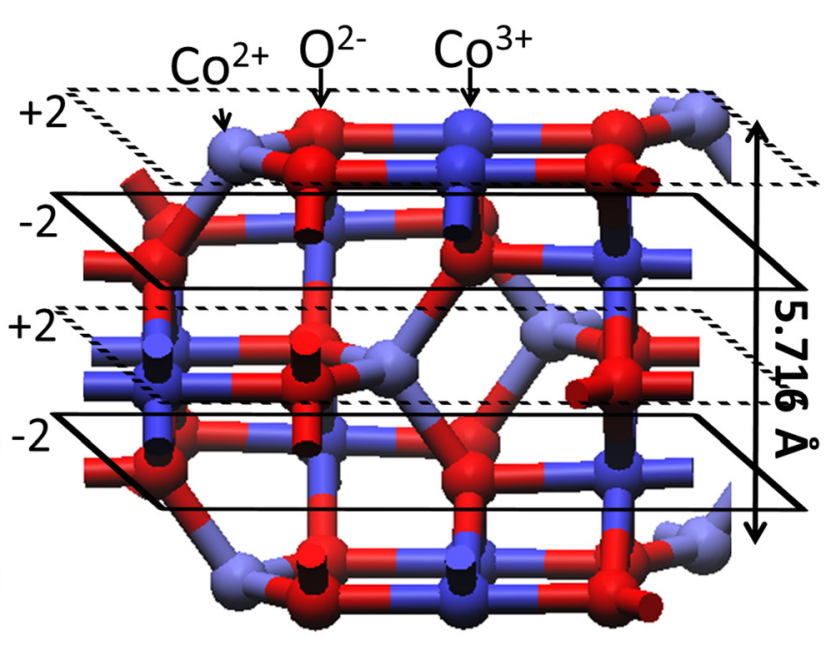

FIG. 2. Right: the (110) direction of $\mathrm{Co}_{3} \mathrm{O}_{4}$ is characterized by a 4-repeat period over a depth of $5.7 \AA$. The alternating planes are shown from a top view on the left. The type A plane is comprised of units of $\mathrm{Co}_{2}^{3+} \mathrm{Co}_{2}^{2+} \mathrm{O}_{4}$ with a formal charge of +2 , while the type $\mathrm{B}$ planes include $\mathrm{Co}^{3+}{ }_{2} \mathrm{O}_{4}$ resulting in a charge of -2 . 
chamber (VG Scienta R3000). For the remaining characterization techniques (AFM, XRD, TEM, Ellipsometry, and SQUID), the samples were removed from UHV and exposed to atmosphere.

Spectroscopic ellipsometry measures the complex Fresnel ratio

$$
\rho=\frac{r_{p}}{r_{s}}=\tan \psi e^{i \Delta}
$$

i.e., the ratio of the p-polarized reflectance $r_{p}$ to the s-polarized reflectance $r_{s} . \rho$ is usually expressed in terms of the ellipsometric angles $\psi$ and $\Delta$. For a bulk sample with complex refractive index $n, \rho$ is given by ${ }^{44,45}$

$$
\rho=\frac{\left(n \cos \phi_{0}-\cos \phi_{1}\right)\left(\cos \phi_{0}+n \cos \phi_{1}\right)}{\left(n \cos \phi_{0}+\cos \phi_{1}\right)\left(\cos \phi_{0}-n \cos \phi_{1}\right)},
$$

where $\phi_{0}$ is the angle of incidence and $\phi_{1}$ the angle of refraction given by Snell's Law.

The imaginary part of the dielectric function $\varepsilon=n^{2}$ is related to absorption in the sample by elementary excitations. For example, the absorption in the infrared (IR) spectral region is given by lattice absorption of infrared-active phonons or the free-carrier response in a metal. In the visible and UV spectral region, the absorption is due to interband electronic transitions. The application of this technique to bulk spinel $\left(\mathrm{MgAl}_{2} \mathrm{O}_{4}\right)$ has been described recently. ${ }^{43}$

In the case of a thin film on a substrate, we can still invert Eq. (2) to calculate $\langle n\rangle$ and $\langle\varepsilon\rangle=\langle n\rangle^{2}$, but these quantities are no longer related to the optical constants of a specific material. Instead, $\langle n\rangle$ and $\langle\varepsilon\rangle$ are determined by the optical constants of the film and the substrate along with the film thickness and surface and interface roughness layer thicknesses. Therefore, $\langle n\rangle$ and $\langle\varepsilon\rangle$ are called the pseudorefractive index and the pseudo-dielectric function. If the dielectric function $\varepsilon_{S}$ of the substrate and the film thickness are known, then the dielectric function $\varepsilon_{f}$ of the film can be determined by fitting the experimental data using wellestablished procedures ${ }^{44,45}$ and commercial software (J.A. Woollam Co., Inc., WVASE32). Surface roughness can also be considered within this approach.

For this work, we used two instruments to acquire our data. From 0.76 to $6.5 \mathrm{eV}$, we measured the ellipsometric angles on a Woollam variable angle-of-incidence spectroscopic ellipsometer (VASE) with computer-controlled Berek waveplate compensator at seven angles of incidence $\left(50^{\circ}\right.$ to $80^{\circ}$ ). For IR ellipsometry, we used a Woollam FTIR-VASE ellipsometer, which is based on a fixed analyzer $\left(0^{\circ}\right.$ and $\left.180^{\circ}\right)$ and polarizer $\left( \pm 45^{\circ}\right)$ and a rotating compensator. We measured from 250 to $7000 \mathrm{~cm}^{-1}$ at five angles of incidence $\left(60^{\circ}\right.$ to $\left.80^{\circ}\right)$. In the FTIR experiments, the spectral resolution was set to $8 \mathrm{~cm}^{-1}$ to improve the signal to noise ratio. All data sets were merged and fitted simultaneously with the same model, including both lattice absorption and interband electronic transitions. The optical constants for the $\mathrm{MgAl}_{2} \mathrm{O}_{4}$ substrate were taken from Ref. 43 without adjustments. We assumed a surface roughness of $2 \AA$, guided by atomic force microscopy measurements. In the case of a thin absorbing $\mathrm{Co}_{3} \mathrm{O}_{4}$ layer on a substrate, the layer thickness cannot be determined. We use a film thickness of $220 \AA$ (determined from the growth parameters and confirmed by $\mathrm{x}$-ray reflectance measurements) as an input for our ellipsometry analysis. Small errors in film thickness cause errors in the amplitude of the dielectric function, but do not affect the peak energies and broadenings.

\section{RESULTS AND DISCUSSION}

The spinel surface was characterized during film deposition using in situ RHEED (Fig. 3). The most stable surface of the $\mathrm{MgAl}_{2} \mathrm{O}_{4}$ (110) substrate is the A-type, which contains both $\mathrm{Mg}$ and $\mathrm{Al}$ atoms. The RHEED pattern for the substrate (Fig. 3(a)) confirms the crystalline quality of the surface, with sharp diffraction maxima as expected for a periodic surface with negligible roughness. As the $\mathrm{Co}_{3} \mathrm{O}_{4}$ film grows (Figs. 3(b) and 3(d)), it follows the termination of the substrate to preserve charge neutrality, as is common in polar materials. ${ }^{27,41}$

The surface roughens with thickness starting between 10 and $20 \AA$, causing broadening of the RHEED streaks. However, as the film continues to grow, the surface again becomes smooth, with a crystalline quality approaching that of the substrate at around $100-\AA$-thickness and above (Fig. $3(d)$ ). One possible explanation for these observations is the electrostatic energy of a polar material diverges with increasing thickness. ${ }^{27,46}$ Above a critical field and therefore critical thickness, the surface roughness may develop to compensate

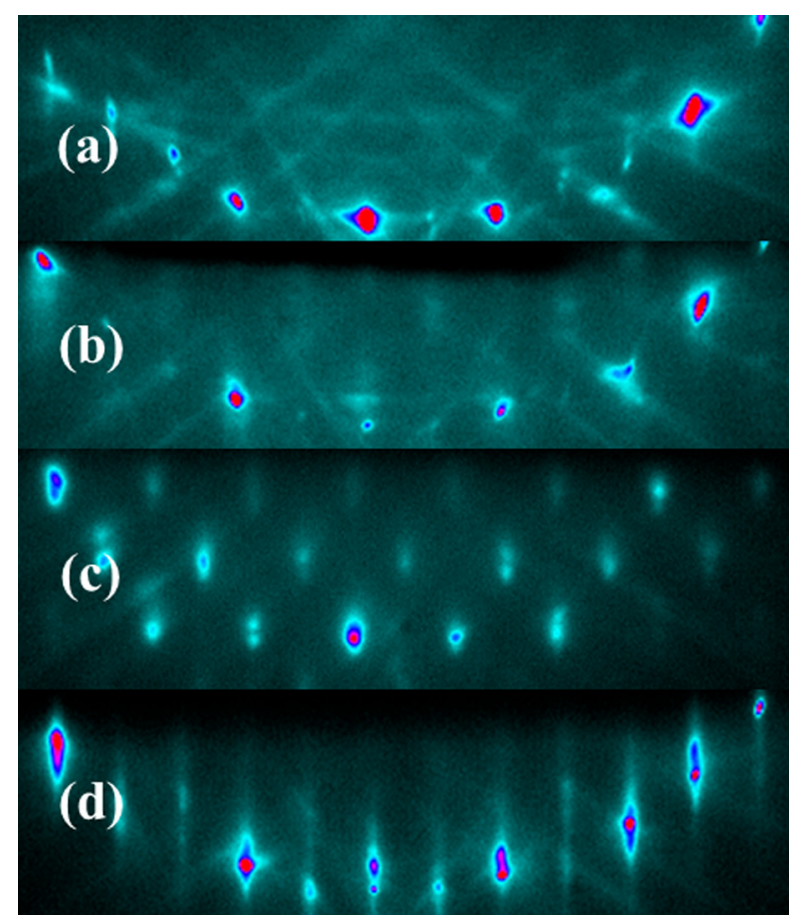

FIG. 3. RHEED patterns along the [110] azimuth at grazing incidence for (a) the $\mathrm{MgAl}_{2} \mathrm{O}_{4}$ substrate, (b) $\sim 13$ - $\AA$-thick $\mathrm{Co}_{3} \mathrm{O}_{4}$ film, (c) $\sim 24$ - $\AA$-thick film, and (d) 125- $\AA$-thick film. The most stable surface of the $\mathrm{MgAl}_{2} \mathrm{O}_{4}$ substrate is the A-type, which contains both $\mathrm{Mg}$ and $\mathrm{Al}$ atoms. The $\mathrm{Co}_{3} \mathrm{O}_{4}$ film follows the termination of the substrate to preserve charge neutrality, as is common in polar materials. The surface develops roughness at thickness starting between 10 and $20 \AA$, causing the observed broadening of the RHEED streaks. The surface again becomes smooth as growth continues, returning to substrate quality around $100 \AA$ thickness. 
the surface charge density. Once the film can instead compensate by bulk rather than surface reconstruction, the surface can once again become smooth, as seen in the thicker films.

These RHEED observations are supported by ex situ AFM measurements for $\mathrm{Co}_{3} \mathrm{O}_{4}$ samples of varying thickness. Scans of $5 \times 5 \mu \mathrm{m}$ areas are shown for the substrate and three representative films in Fig. 3. For the $\sim 13$ - $\AA$-thick film (Figs. 3(b) and 4(b)), the RMS roughness was $1.26 \AA$. This is on the order of instrumental resolution; any perceived modulation of the surface is likely due to vibrations of the microscope. For slightly thicker films, such as the $\sim 24 \AA$ film (Figs. 2(c) and 3(c)), the surface becomes noticeably rougher. In this sample, the RMS roughness increased to $5.26 \AA$. Finally, the $125 \AA$ film shown in Fig. 4(d) shows the surface roughness has decreased back down to $1.04 \AA$; this sample serves as a representative example of the smoothening that occurs in thicker films.

$\mathrm{X}$-ray diffraction measurements were carried out using a Panalytical X'PERT Pro diffractometer $(\mathrm{Cu} \mathrm{K} \alpha 1$ source, $\lambda=1.5406 \AA$ ) operating at $45 \mathrm{kV}$ and $40 \mathrm{~mA}$. The symmetric $2 \theta-\theta$ scan shows strong substrate peaks corresponding to an out-of-plane lattice constant of $8.07 \AA$. The highresolution rocking curve of the (440) reflection for a $240-\AA$ thick film $\mathrm{Co}_{3} \mathrm{O}_{4}$ is shown in Fig. 5(a). Experimental data points are shown by open circles, and a sum of two Voigt functions has been fitted to the data (blue curve). The contribution from the substrate (red curve) is mostly Gaussian, with a width of $0.015^{\circ}$, on the order of instrumental resolution as expected for a single-crystal substrate. The film peak (green curve) has a width $0.03^{\circ}$, not much broader than that of the substrate. The shaded green area outlines values within the uncertainty of the position of the film peak, showing that the film is nearly lattice-matched to the substrate. Spot spacing in RHEED indicates that there is no change in the in-plane lattice constant for the film compared to the substrate up to the thickness that we have grown $(250 \AA)$.

All thicknesses referenced above were first estimated from the quartz crystal microbalance calibration and verified by X-ray reflectivity (XRR). In this geometry, oscillations in
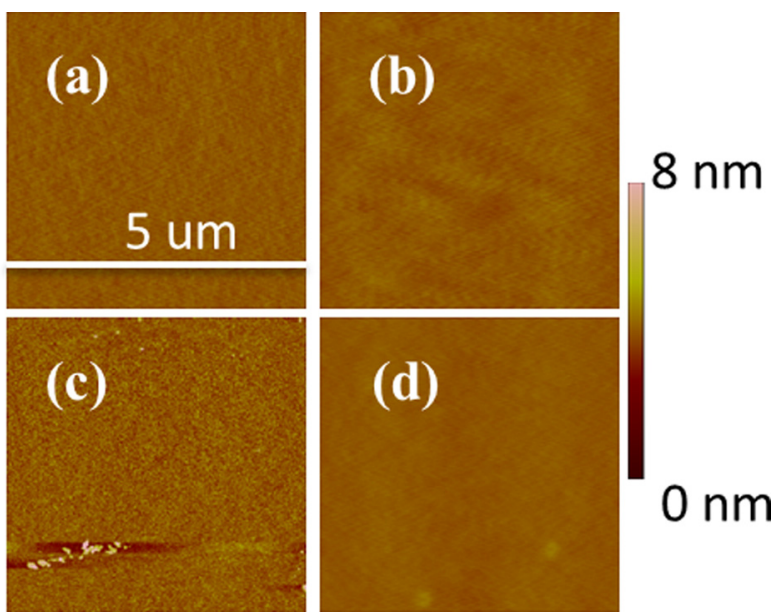

FIG. 4. AFM measurements for: (a) bare $\mathrm{MgAl}_{2} \mathrm{O}_{4}$ substrate, followed by $\mathrm{Co}_{3} \mathrm{O}_{4}$ samples of thickness (b) $13 \AA$, (c) $24 \AA$, and (d) $125 \AA$. The RMS roughness measured was $1.52 \AA, 1.26 \AA$, $5.26 \AA$, and $1.04 \AA$, respectively.
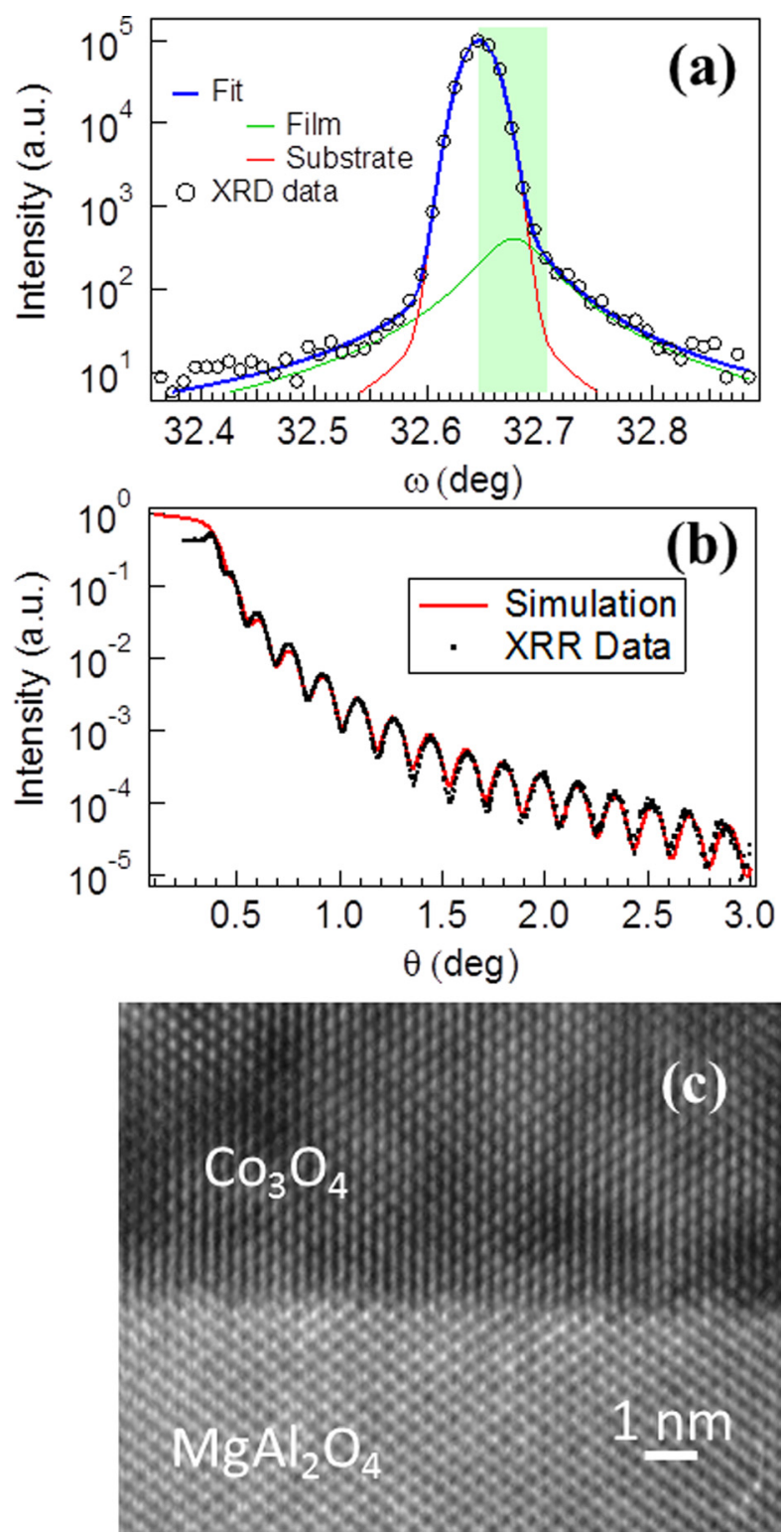

FIG. 5. (a) Rocking curve data and analysis of the (440) reflection of $240 \AA$ film $\left(\mathrm{Co}_{3} \mathrm{O}_{4}\right.$ on $\left.\mathrm{MgAl}_{2} \mathrm{O}_{4}\right)$. Experimental data points are shown by open circles, and a sum of two Voigt functions has been fitted to the data. (b) Xray reflectivity for the same film. The drawn (red) line is a simulation. Oscillations due to the difference in density between the substrate and film persist undamped to high angles, implying a smooth surface and abrupt interface. (c) High-resolution cross-sectional transmission electron micrograph confirms the abrupt interface between the crystalline substrate and film.

the reflected intensity arise due to the difference in density between the substrate and film. An example is shown for the same $240 \AA$ film (Fig. 5(b)); the black line is experimental data, while the drawn (red) line is a simulation. The simulated oscillations correspond to a film thickness of $240 \AA$ with 1 A roughness. Strong oscillations with minimal damping are indicative of a smooth surface and abrupt interface for the as-grown sample.

To further characterize the interface, Fig. 5(c) shows a cross-sectional transmission electron micrograph taken with a JEOL JEM-4000EX high-resolution electron microscope operated at $400 \mathrm{keV}$. The image shows a highly crystalline epitaxial $\mathrm{Co}_{3} \mathrm{O}_{4}$ film on the $\mathrm{MgAl}_{2} \mathrm{O}_{4}$ substrate with a sharp 
and coherent interface, in agreement with the RHEED and XRD results above.

XPS measurements were performed in situ using monochromatic $\mathrm{Al} \mathrm{K} \alpha$ radiation ( $\mathrm{h} \nu=1486.6 \mathrm{eV}$ ). To avoid charging due to the highly insulating substrate, a low-energy electron flood gun was used to replace the emitted electrons. Fig. 6 summarizes the core level spectroscopy. A representative survey scan of a bulk-like 250 - $\AA$-thick $\mathrm{Co}_{3} \mathrm{O}_{4}$ film shows the expected peaks of a system dominated by cobalt and oxygen (Fig. 6(a)). Higher-resolution scans of the $\mathrm{O} 1 \mathrm{~s}$
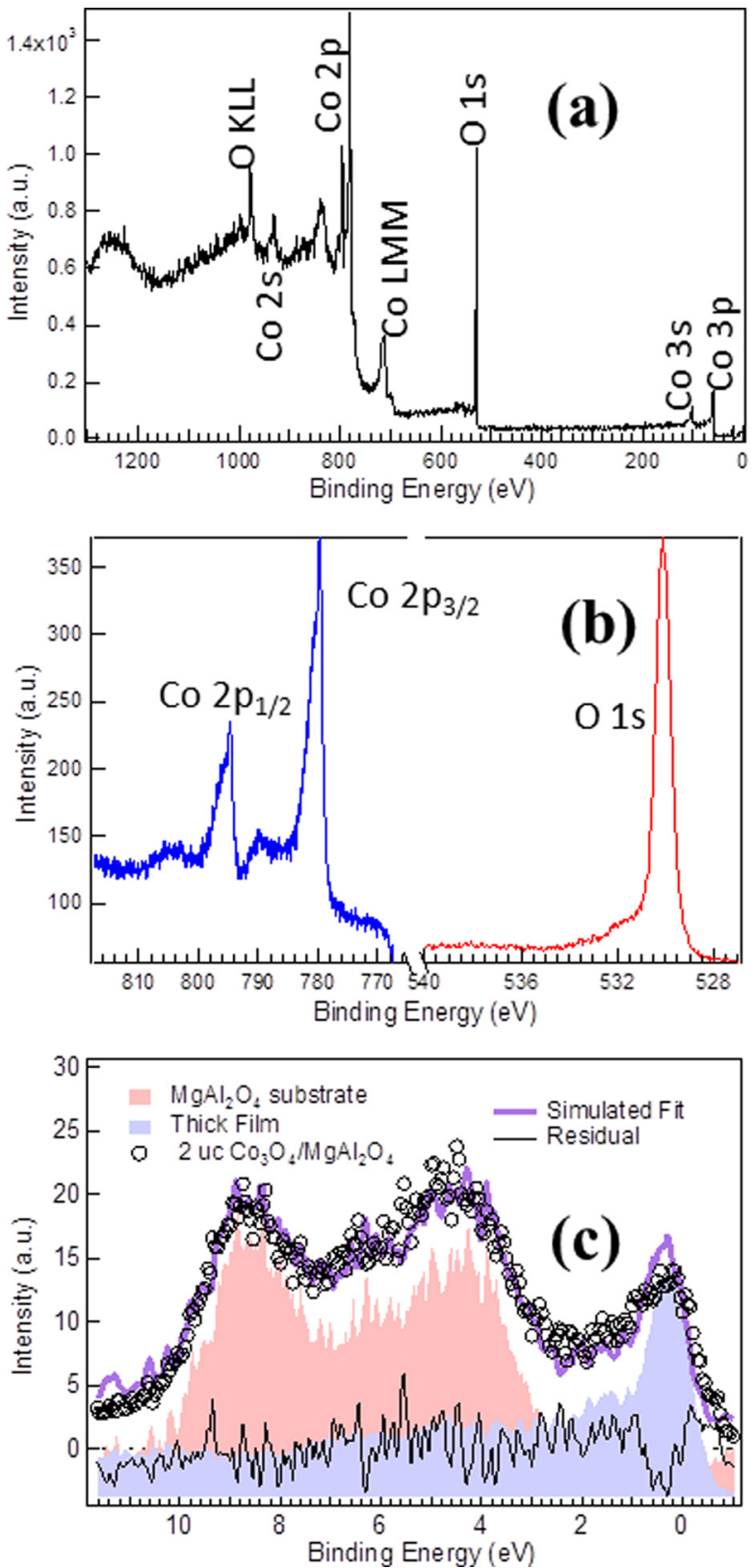

FIG. 6. XPS spectra. (a) Survey scan of representative 250- $\AA$-thick $\mathrm{Co}_{3} \mathrm{O}_{4}$ film shows a spectrum dominated by cobalt and oxygen. (b) High-resolution Co $2 p$ scan shows characteristic strongly suppressed shake-up satellite peaks at $+5.5 \mathrm{eV}$ and $+9 \mathrm{eV}$, as compared to $\mathrm{CoO}$. The $\mathrm{O} 1 \mathrm{~s}$ peak shows a slight shoulder, which can be attributed to surface oxygen. (c) To determine the valence band offset, the spectra for pure $\mathrm{MgAl}_{2} \mathrm{O}_{4}$ (red shading) and $\mathrm{Co}_{3} \mathrm{O}_{4}$ (blue shading) were scaled, offset, and added together to create a simulated fit (purple line) to the measured valence band spectra for a heterostructure of $13 \mathrm{~A} \mathrm{Co}_{3} \mathrm{O}_{4}$ on $\mathrm{MgAl}_{2} \mathrm{O}_{4}$ (black open circles). The residual difference is also plotted (black line). and Co 2p peaks are shown in Fig. 6(b). Spectra have been artificially shifted to fix the location of the $\mathrm{O} 1 \mathrm{~s}$ peak at $530.1 \mathrm{eV}$. The Co $2 \mathrm{p}$ scan shows characteristic strongly suppressed shake-up satellite peaks at $+5.5 \mathrm{eV}$ and $+9 \mathrm{eV}$ as compared to $\mathrm{CoO}{ }^{15}$

Fig. 6(c) displays XPS valence band spectra for the bare $\mathrm{MgAl}_{2} \mathrm{O}_{4}$ substrate (red shading) and 250- $\AA$-thick $\mathrm{Co}_{3} \mathrm{O}_{4}$ film (blue shading). The band offset in $\mathrm{Co}_{3} \mathrm{O}_{4}$ heterostructures may facilitate understanding of the catalytic properties of $\mathrm{Co}_{3} \mathrm{O}_{4}$; for example, in order to achieve a spontaneous water splitting reaction, both a small band gap and suitable alignment of band edges with respect to the water redox potentials are required. ${ }^{14}$ Band offsets were calculated by both core-level ${ }^{14}$ and valence band ${ }^{47,48}$ spectroscopy. The valence band maximum $\left(\mathrm{E}_{\mathrm{VBM}}\right)$ for each material was calculated using the linear extrapolation method. ${ }^{49}$ By comparing energy offsets between the Co $2 \mathrm{p}, \mathrm{Al} 2 \mathrm{p}$, and valence band edge positions (as summarized in Table I) using

$$
\begin{aligned}
V B O_{C L}= & \left(E_{C O 2 p}-E_{V B M}\right)_{\mathrm{CO}_{3} \mathrm{O}_{4}}-\left(E_{\mathrm{Al2p}}-E_{V B M}\right)_{\mathrm{MgAl}_{2} \mathrm{O}_{4}} \\
& -\left(E_{\mathrm{Co} 2 \mathrm{p}}-E_{\mathrm{Al} 2 \mathrm{p}}\right)_{\mathrm{CO}_{3} \mathrm{O}_{4} / \mathrm{MgAl}_{2} \mathrm{O}_{4}},
\end{aligned}
$$

we calculate a $\mathrm{VBO}_{\mathrm{CL}}$ of $3.4 \mathrm{eV}$.

The VBO can also be determined directly from the valence band spectra. ${ }^{47,48}$ For a heterostructure of $13 \AA \mathrm{Co}_{3} \mathrm{O}_{4} /$ $\mathrm{MgAl}_{2} \mathrm{O}_{4}$, a contribution from the film is visible along with an attenuated contribution from the substrate (Fig. 6(c), black open circles). We simulated a fit (purple solid line) to the heterostructure by scaling and offsetting the pure valence band spectra measured for the $\mathrm{MgAl}_{2} \mathrm{O}_{4}$ substrate and thick $\mathrm{Co}_{3} \mathrm{O}_{4}$ film. This method uses an "all at once" fit minimizing $\chi^{2}$ by the Levenberg-Marquardt algorithm implemented in Igor Pro software (WaveMetrics, Lake Oswego, OR). The difference between the measured and simulated spectra is also plotted (black line). Using this method, we calculate $\mathrm{VBO}_{\text {sim }}=3.2 \mathrm{eV}$, in good agreement with the offset calculated above by the core levels.

We modeled the electronic structure of bulk $\mathrm{Co}_{3} \mathrm{O}_{4}$ using the Hubbard-corrected local density approximation $(\mathrm{LDA}+\mathrm{U})$ to DFT. The problem is difficult, as two different oxidation states of Co with two different spin states must be described. Because of this, U-values for $\mathrm{Co}_{3} \mathrm{O}_{4}$ calculations vary widely in the literature. ${ }^{18,50-52}$ The problem is further complicated by the debate over the size of the fundamental band gap of $\mathrm{Co}_{3} \mathrm{O}_{4}$.

To identify a combination of $U$ which best matches experimental data, we started with the Shirley-background-subtracted XPS valence band (Fig. 7(a), blue open circles) and fit 5 peaks to the data (Fig. 7(a), blue shaded regions). 5

TABLE I. XPS core levels for valence band offset calculation.

\begin{tabular}{lccc}
\hline \hline Materials & $\begin{array}{c}\mathrm{MgAl}_{2} \mathrm{O}_{4} \\
\text { substrate }\end{array}$ & $\begin{array}{c}\sim 13 \AA \\
\mathrm{Co}_{3} \mathrm{O}_{4} / \mathrm{MgAl}_{2} \mathrm{O}_{4}\end{array}$ & $\begin{array}{c}\mathrm{Co}_{3} \mathrm{O}_{4} \\
\text { thick film }\end{array}$ \\
\hline $\mathrm{Co} 2 p(\mathrm{eV})$ & $\ldots$ & 777.02 & 777.87 \\
$\mathrm{Al} 2 p(\mathrm{eV})$ & 74.40 & 74.65 & $\ldots$ \\
$\mathrm{VBM}(\mathrm{eV})$ & 3.17 & $\ldots$ & 0.852 \\
\hline \hline
\end{tabular}


(b)
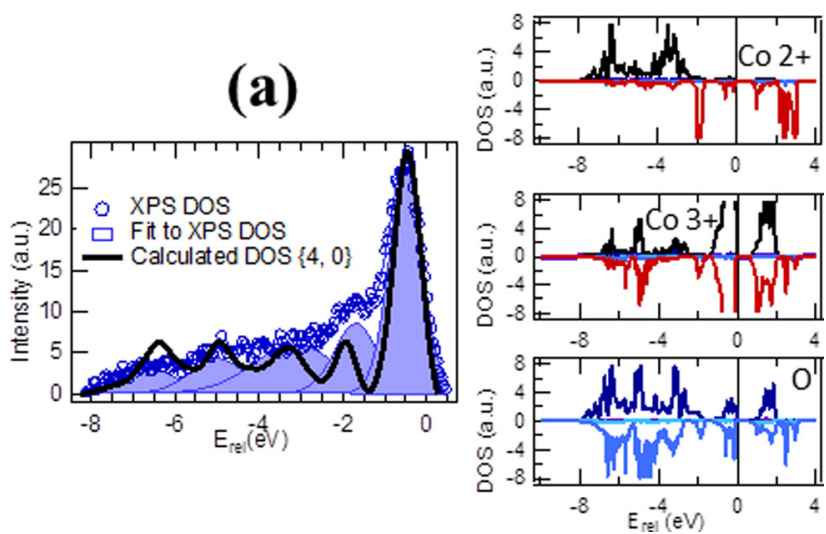

FIG. 7. Valence band structure. (a) Measured XPS valence band for a 250A-thick sample is shown by open circles, with the envelope of the 5-peak fit shaded blue. Indicated by the solid black line, calculated DOS for bulk $\mathrm{Co}_{3} \mathrm{O}_{4}$ with $\mathrm{U}\left(\mathrm{Co}^{2+}\right)=4 \mathrm{eV}$ and $\mathrm{U}\left(\mathrm{Co}^{3+}\right)=0 \mathrm{eV}$ agrees well with experimental features. (b) Site- and orbital-projected DOS for $\mathrm{U}\left(\mathrm{Co}^{2+}\right)=4 \mathrm{eV}$ and $\mathrm{U}\left(\mathrm{Co}^{3+}\right)=0 \mathrm{eV}$.

peaks was the minimum number necessary to acquire a reasonable fit. We then calculated the total density of states (DOS) for 64 combinations of $\mathrm{U}$ (from 0 to $7 \mathrm{eV}$ on $\mathrm{Co}^{2+}$ and $\mathrm{Co}^{3+}$ in $1 \mathrm{eV}$ increments), broadened each DOS by $0.5 \mathrm{eV}$ to account for experimental broadening, and again fit 5 peaks to each DOS. We then compared the overall band width and peak positions with the experimental data, narrowing down from the 64 original possible combinations to 3 best fits: $\left\{\mathrm{U}\left(\mathrm{Co}^{2+}\right), \mathrm{U}\left(\mathrm{Co}^{3+}\right)\right\}=\{0,0\},\{0,3\}$, and $\{4,0\}$. We then checked the magnetization as a function of the two $\mathrm{U}$ parameters. Combination $\{4,0\}$ produced a magnetization of $2.65 \mu_{\mathrm{B}}$ for the $\mathrm{Co}^{2+}$ ions, while $\{0,0\}$ and $\{0,3\}$ produce lower values of 2.33 and $2.42 \mu_{\mathrm{B}}$, respectively, with the remaining moment on the nonmagnetic $\mathrm{Co}^{3+}$ ions. Therefore, based on the peak positions and magnetic moment, we selected $\left\{\mathrm{U}\left(\mathrm{Co}^{2+}\right), \mathrm{U}\left(\mathrm{Co}^{3+}\right)\right\}=\{4,0\}$ for our calculations.

As shown in Fig. 7(a), after scaling by photoionization cross-section, ${ }^{53}$ the peak positions, valence band width, and relative peak intensities of the calculated DOS (solid black line) are in good agreement with the XPS valence band. Siteand orbital-projected DOS for $\left\{\mathrm{U}\left(\mathrm{Co}^{2+}\right), \mathrm{U}\left(\mathrm{Co}^{3+}\right)\right\}=\{4,0\}$ are shown in Fig. 7(b). Comparing with the literature, our $\mathrm{U}\left(\mathrm{Co}^{2+}\right)$ value agrees with the value used by Chen et al., ${ }^{51,52}$ while our $\mathrm{U}\left(\mathrm{Co}^{3+}\right)$ value agrees with that of Qiao et al. ${ }^{18} \mathrm{We}$ calculate a band gap of $0.6 \mathrm{eV}$, in agreement with the recent transmission measurements from Qiao et al. ${ }^{18}$ The valence band features are dominated by contributions from $\mathrm{Co}^{2+}$ and $\mathrm{Co}^{3+} \mathrm{d}$ states and $\mathrm{O} 2 \mathrm{p}$ states, with strong hybridization between these orbitals. The top of the valence band is mostly composed of $\mathrm{Co}^{3+} \mathrm{d}$ and $\mathrm{O} 2 \mathrm{p}$ states, while the main $\mathrm{O} 2 \mathrm{p}$ states lie deeper in the valence band. The bottom of the conduction band has contributions from $\mathrm{Co}^{2+}$ and $\mathrm{Co}^{3+} \mathrm{d}$ states as well as $\mathrm{O} 2 \mathrm{p}$ states. The presence of $\mathrm{Co}^{3+} \mathrm{d}$ states at the top of the valence band is in agreement with the assignments of Kim and Park. ${ }^{19,50}$ Since both $\mathrm{Co}^{2+}$ and $\mathrm{Co}^{3+} \mathrm{d}$ states are present at the conduction band minimum, we cannot resolve whether the gap originates from an on-site or cross-site transition.

The pseudo-dielectric function $\langle\varepsilon\rangle$ for a 220 - $\AA$-thick $\mathrm{Co}_{3} \mathrm{O}_{4}$ epilayer on spinel is shown in Fig. 8. It is nearly independent of the angle of incidence. Also, the data from both instruments are well matched in the area of overlap near $0.8 \mathrm{eV}$. As mentioned above, $\langle\varepsilon\rangle$ is not representative of the optical constants for $\mathrm{Co}_{3} \mathrm{O}_{4}$. Instead, it combines features of the layer and the substrate. For example, at low energies (near $0.5 \mathrm{eV}$, below the band gap of the film), $\left\langle\varepsilon_{1}\right\rangle=2.9$, which is determined by the optical constants of the spinel substrate. ${ }^{43}$ At intermediate energies (between 0.7 and $3 \mathrm{eV}$ ), the $\mathrm{Co}_{3} \mathrm{O}_{4}$ film causes interference effects and the absorption peaks of $\mathrm{Co}_{3} \mathrm{O}_{4}$ appear as peaks in $\left\langle\varepsilon_{1}\right\rangle$. (In a bulk material, absorption causes peaks in $\left\langle\varepsilon_{2}\right\rangle$.) In the UV region, the absorption of the $\mathrm{Co}_{3} \mathrm{O}_{4}$ film is very large and interference effects decrease. Therefore, $\left\langle\varepsilon_{1}\right\rangle$ resembles the dielectric function of the $\mathrm{Co}_{3} \mathrm{O}_{4}$. We also note that interference effects cause $\left\langle\varepsilon_{2}\right\rangle$ to be negative below $2.5 \mathrm{eV}$, where the absorption of $\mathrm{Co}_{3} \mathrm{O}_{4}$ is related to minima of $\left\langle\varepsilon_{2}\right\rangle$. At higher energies, it causes maxima.

The optical constants of the $\mathrm{Co}_{3} \mathrm{O}_{4}$ epilayer can be determined using well-known procedures, ${ }^{44,45}$ since the film thickness and the optical constants of the spinel substrate are known. ${ }^{43}$ We write the dielectric function $\varepsilon$ as a sum of Kramers-Kronig consistent oscillators and vary the oscillator parameters until we reach good agreement between the data (symbols) and model (solid lines) in Fig. 8. The details of the expansion are not important and the fit parameters are not physically meaningful.

The resulting dielectric function $\varepsilon$ of $\mathrm{Co}_{3} \mathrm{O}_{4}$ is shown in Fig. 9. These optical constants are available as supplemental material. ${ }^{59}$ We see that $\mathrm{Co}_{3} \mathrm{O}_{4}$ is an insulator, since $\varepsilon$ vanishes at low energies. It has a direct band gap (onset of strong absorption) of $0.75 \mathrm{eV}$. An indirect band gap or defect absorption is not visible with ellipsometry, since the resulting absorption coefficient is very small. The first absorption peak (maximum in the joint density of states for allowed interband optical transitions) occurs at $0.9 \mathrm{eV}$. Since we merge data sets from two instruments in this spectral region, there is an artifact in the data, which shows a double-peak

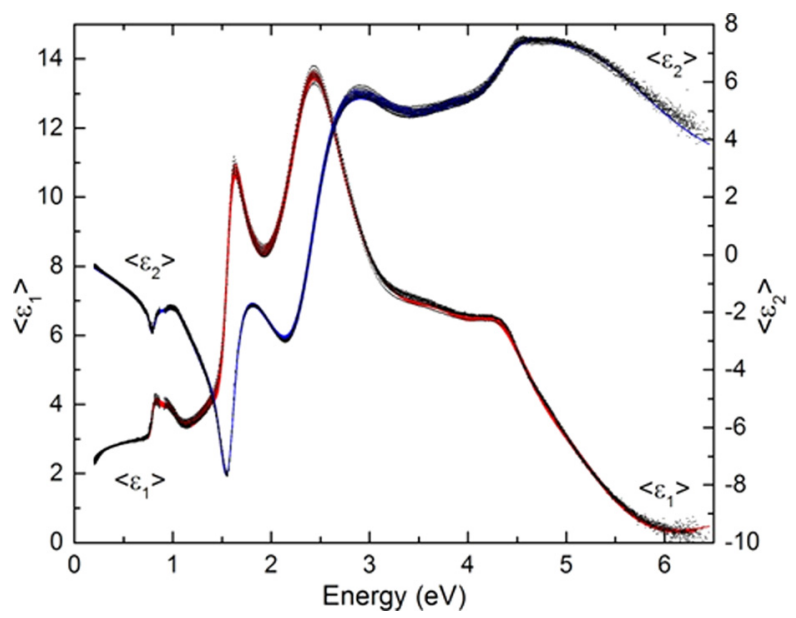

FIG. 8. Pseudodielectric function $\langle\varepsilon\rangle$ of a 220 - $\AA$-thick $\mathrm{Co}_{3} \mathrm{O}_{4}$ film on spinel. Symbols: Experimental data. Lines: Fit with the dielectric function shown in Fig. 9. 


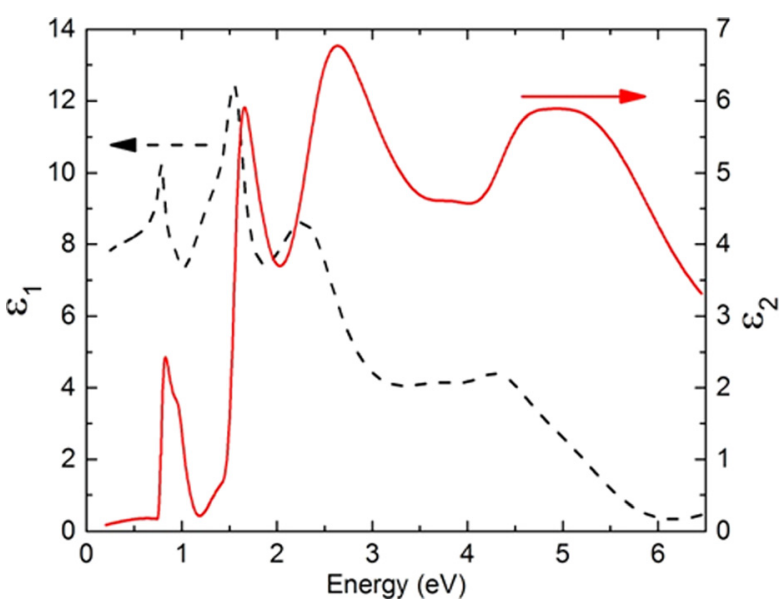

FIG. 9. Real (dashed) and imaginary (solid) parts of the dielectric function $\varepsilon$ of $\mathrm{Co}_{3} \mathrm{O}_{4}(220$ - $\AA$-thick film grown by MBE) from the near-IR to the nearUV region, showing peaks due to interband electronic transitions. The band gap for this $\mathrm{Co}_{3} \mathrm{O}_{4}$ film is $0.75 \mathrm{eV}$.

structure near $0.9 \mathrm{eV}$. (A double peak was also suggested in density-functional calculations ${ }^{18}$ but we are unable to confirm this with our current experiments. More precise work, including low-temperature ellipsometry measurements optimized for the near-infrared spectral region are needed.) The absorption then drops and reaches a minimum at $1.2 \mathrm{eV}$. There is a second onset of strong absorption near $1.4 \mathrm{eV}$, which has been associated with the direct band gap in previous studies. ${ }^{19,20}$ The strong absorption peak at $0.9 \mathrm{eV}$ was not identified in some of the earlier work because of the limited spectral range in some previous experiments. On the other hand, our results are in excellent agreement with those of Ref. 18, where a band gap of $0.74 \mathrm{eV}$ is reported from transmission and photoluminescence measurements. It has been $\operatorname{argued}^{18}$ that this gap is due to direct dipole-forbidden $\mathrm{d}-\mathrm{d}$ intraband transitions at tetrahedral-site $\mathrm{Co}^{2+}$ cations. These transitions (forbidden in the presence of perfect spherical symmetry) become allowed due to crystal-field splitting in the cubic spinel structure and due to hybridization of the oxygen $2 \mathrm{p}$ states with the cobalt $3 \mathrm{~d}$ states. See the projected DOS shown in Fig. 7(b) for comparison. Our calculations also find substantial $\mathrm{Co}^{3+}$ contributions to the valence band maximum and the conduction band minimum. Therefore, we also expect contributions to $\mathrm{d}$ to $\mathrm{d}$ intraband transitions from the $\mathrm{Co}^{3+}$ sites.

The higher-energy peaks at 1.65 and $2.6 \mathrm{eV}$ were previously identified by Kim and Park. ${ }^{19}$ Our work shows an additional broad absorption peak at $5 \mathrm{eV}$, comparable to Ref. 18 . At even higher energies, $\varepsilon_{2}$ drops significantly.

The ellipsometric angles in the region of the lattice absorption by infrared active phonons in the $\mathrm{Co}_{3} \mathrm{O}_{4}$ epilayer and the spinel $\mathrm{MgAl}_{2} \mathrm{O}_{4}$ substrate are shown in Fig. 10. The data (symbols) can be described with a model (lines) consisting of a spinel substrate and a layer, in which the lattice absorption is written as a sum of Lorentzian lineshapes. ${ }^{43}$

The spectra are very similar to those of bulk spinel (see Fig. 10 in Ref. 43) with four notable exceptions due to the presence of the $\mathrm{Co}_{3} \mathrm{O}_{4}$ epilayer: (1) There is a dip in the first reststrahlen band $\psi$ at $555 \mathrm{~cm}^{-1}$ because of a strong $\mathrm{Co}_{3} \mathrm{O}_{4}$ phonon. (2) At $982 \mathrm{~cm}^{-1}, \psi$ becomes larger than $45^{\circ}$, where

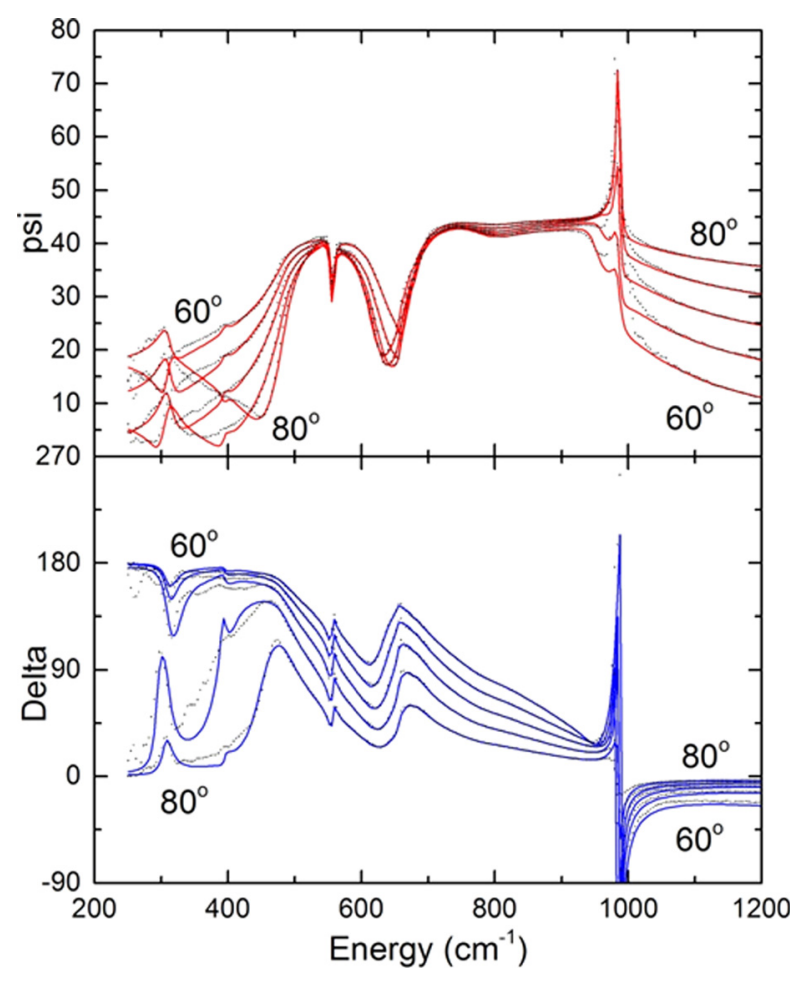

FIG. 10. Ellipsometric angles for a 220 - $\AA$-thick $\mathrm{Co}_{3} \mathrm{O}_{4}$ film on spinel in the mid-infrared spectral region at five angles of incidence from $60^{\circ}$ to $80^{\circ}$. (Symbols: Experimental data. Lines: Fit with a Lorentz oscillator expansion of the $\mathrm{Co}_{3} \mathrm{O}_{4}$ lattice absorption.)

the dielectric function of the substrate is close to 1 at an LO peak of the substrate. This is an interference effect. For a bulk material, $\psi$ is always below $45^{\circ}$. (3) $\mathrm{A} \mathrm{Co}_{3} \mathrm{O}_{4} \mathrm{TO}$ phonon at $655 \mathrm{~cm}^{-1}$ causes a tiny modification in the rise of the second reststrahlen band. (4) The fit is not good below $400 \mathrm{~cm}^{-1}$, which was attributed to cation disorder in the earlier work on spinel. ${ }^{43}$ Nevertheless, we are able to find a small feature in $\psi$ at $395 \mathrm{~cm}^{-1}$, where $\mathrm{a} \mathrm{Co}_{3} \mathrm{O}_{4}$ phonon is expected. In summary, we find $\mathrm{Co}_{3} \mathrm{O}_{4}$ phonon peaks at 395 , 557 , and $656 \mathrm{~cm}^{-1}$, in agreement with FTIR reflectance and electron energy loss measurements. ${ }^{20,54,55}$ In the spinel structure, we expect four infrared-active TO phonons. ${ }^{43}$ For $\mathrm{Co}_{3} \mathrm{O}_{4}$, the literature also reports an infrared-active $\mathrm{T}_{1 \mathrm{u}}$ phonon at $214 \mathrm{~cm}^{-1}$, which is below the spectral range of our infrared ellipsometer and therefore was not observed by us.

In Fig. 11, we show an estimate for the mid-IR dielectric function of $\mathrm{Co}_{3} \mathrm{O}_{4}$, which was obtained from the fit to the data in Fig. 10. The peak at $395 \mathrm{~cm}^{-1}$ is influenced by cation disorder in the substrate. The peak at $656 \mathrm{~cm}^{-1}$ is close to a TO mode in the substrate. Therefore, the amplitudes, positions, and broadenings of these peaks are not very accurate. On the other hand, the $\mathrm{Co}_{3} \mathrm{O}_{4}$ TO peak at $557 \mathrm{~cm}^{-1}$ is not influenced by any substrate features and can be determined with good accuracy. The Lorentzian broadening of this TO peak is about $6 \mathrm{~cm}^{-1}$, limited by the spectral resolution $\left(8 \mathrm{~cm}^{-1}\right)$ of our experiment.

We do not observe any signs of a metallic response, which would lead to discrepancies between our latticedynamical model and the data at low frequencies. Therefore, we are unable to investigate a two-dimensional electron gas, which might be present at the interface between $\mathrm{Co}_{3} \mathrm{O}_{4}$ and 


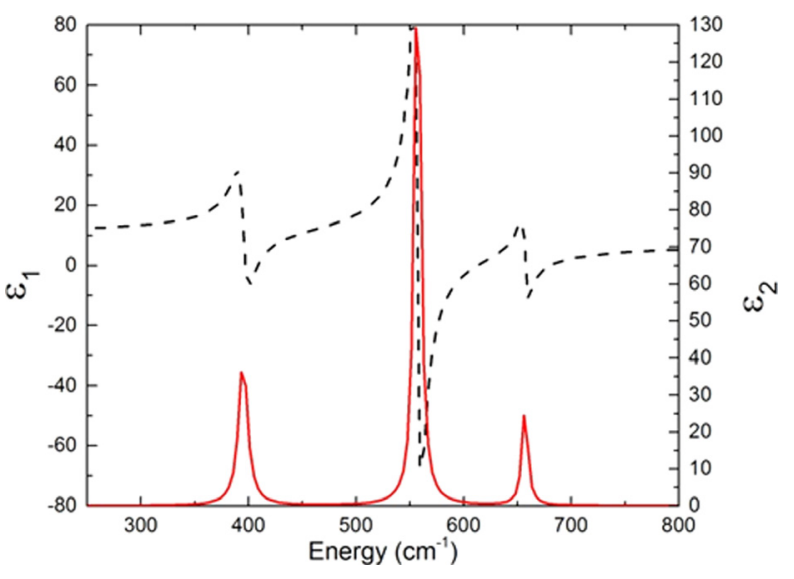

FIG. 11. Real (dashed) and imaginary (solid) parts of the dielectric function of $\mathrm{Co}_{3} \mathrm{O}_{4}$ in the mid-IR, showing lattice absorption by three infrared-active phonons.

$\mathrm{MgAl}_{2} \mathrm{O}_{4}$. Also, we do not find any signs of free carriers due to doping in the $\mathrm{Co}_{3} \mathrm{O}_{4}$ layer. (Other $\mathrm{Co}_{3} \mathrm{O}_{4}$ layers were reported to be $p$-type. ${ }^{18}$ )

Finally, magnetization of a $240-\AA$-thick $\mathrm{Co}_{3} \mathrm{O}_{4}$ (110) film was measured as a function of temperature under zerofield-cooled conditions at a constant magnetic field of $1 \mathrm{~T}$ oriented in-plane (Fig. 12). Field-cooled measurements were in good agreement with the zero-field-cooled values. The data can be attributed to contributions from the relatively small signal from the sample, the diamagnetic substrate, ${ }^{56}$ backing, and the sample mount. Despite the strong background contribution, a local maximum in the magnetization is clearly visible at $49 \mathrm{~K}$. This value is higher than the Néel temperature $\mathrm{T}_{\mathrm{N}} \approx 40 \mathrm{~K}$ for a $\mathrm{Co}_{3} \mathrm{O}_{4}$ crystal. $^{23}$ The $\mathrm{T}_{\mathrm{N}}$ enhancement appears due to the stress created by latticeparameter mismatch between $\mathrm{Co}_{3} \mathrm{O}_{4}$ and $\mathrm{MgAl}_{2} \mathrm{O}_{4}$. Since the lattice parameter of $\mathrm{Co}_{3} \mathrm{O}_{4}$ is slightly smaller than that of $\mathrm{MgAl}_{2} \mathrm{O}_{4}$, the mismatch places $\mathrm{Co}_{3} \mathrm{O}_{4}$ under a tensile stress. It has been widely observed that $\mathrm{T}_{\mathrm{N}}$ in antiferromagnetic oxides including $\mathrm{Co}_{3} \mathrm{O}_{4}$ increases under high pressure. ${ }^{57,58}$

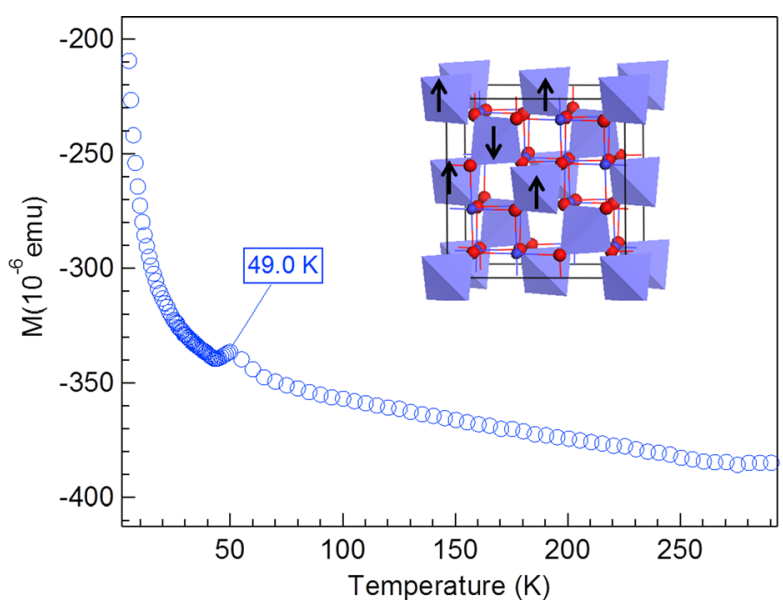

FIG. 12. Magnetization of a $240-\AA$-thick $\mathrm{Co}_{3} \mathrm{O}_{4}$ (110) film was measured as a function of temperature under zero-field-cooled conditions (blue circles) with constant in-plane magnetic field of $1 \mathrm{~T}$. Field-cooled data show similar characteristics. The onset of antiferromagnetism is labeled at $49 \mathrm{~K}$. Inset image shows G-type antiferromagnetic ordering in the spinel structure. The overall negative magnetization is from the diamagnetic contribution from the substrate.
Why a tensile stress increases $T_{N}$ in a G-type antiferromagnet deserves further study. Alternatively, an enhanced $\mathrm{T}_{\mathrm{N}}$ could be related to variations in the oxygen stoichiometry.

\section{CONCLUSION}

In conclusion, we have grown $\mathrm{Co}_{3} \mathrm{O}_{4}$ films on $\mathrm{MgAl}_{2} \mathrm{O}_{4}$ (110) using MBE. We investigated surface roughness and smoothening during growth with RHEED and AFM, and further affirm the high quality and sharp interface of the asgrown film by XRD and TEM. Ellipsometry measurements find a small gap of $0.75 \mathrm{eV}$, in good agreement with DFT calculations based on the shape of the XPS valence band. A valence band offset of $3.2 \mathrm{eV}$ is measured for the heterostructure. Finally, we find that the films are antiferromagnetic with a transition temperature of $49 \mathrm{~K}$, higher than the typical bulk value. These results motivate future study of this material, including DFT/TEM study to determine atomic positions at the interface and surface, low-temperature ellipsometry and optical Hall-effect measurements, and growth on different substrates to study changes in the magnetic properties, band offsets, and catalytic activity.

\section{ACKNOWLEDGMENTS}

We thank Richard Hatch for helpful discussions. The work at UT and ASU was supported by the Air Force Office of Scientific Research (FA9550-12-10494), the Texas Advanced Computing Center, the National Science Foundation (DMR-1122603), and in part by the program "Understanding Charge Separation and Transfer at Interfaces in Energy Materials (EFRC: CST)," an Energy Frontier Research Center funded by the U.S. Department of Energy Office of Science, Office of Basic Energy Sciences, under Award No. DESC0001091. The work at NMSU was supported by the National Science Foundation (DMR1104934). The FTIR ellipsometry measurements were performed at the Center for Integrated Nanotechnologies, an Office of Science User Facility operated for the U.S. Department of Energy (DOE) Office of Science by Sandia National Laboratory (Contract DE-AC04-94AL85000).

${ }^{1}$ G. Eranna, B. C. Joshi, D. P. Runthala, and R. P. Gupta, Crit. Rev. Solid State Mater. Sci. 29, 111 (2004).

${ }^{2}$ W. Y. Li, L. N. Xu, and J. Chen, Adv. Funct. Mater. 15, 851 (2005).

${ }^{3}$ J. A. Moyer, C. A. F. Vaz, D. A. Arena, D. Kumah, E. Negusse, and V. E. Henrich, Phys. Rev. B 84, 054447 (2011).

${ }^{4}$ M. S. Martín-González, J. F. Fernández, F. Rubio-Marcos, I. Lorite, J. L. Costa-Kraümer, A. Quesada, M. A. Bañares, and J. L. G. Fierro, J. Appl. Phys. 103, 083905 (2008).

${ }^{5}$ A. Posadas, M. Berg, H. Seo, D. J. Smith, A. P. Kirk, D. Zhernokletov, R. M. Wallace, A. de Lozanne, and A. A. Demkov, Microelectron. Eng. 88, 1444 (2011).

${ }^{6}$ A. Posadas, M. Berg, H. Seo, A. de Lozanne, A. A. Demkov, D. J. Smith, A. P. Kirk, D. Zhernokletov, and R. M. Wallace, Appl. Phys. Lett. 98, 053104 (2011).

${ }^{7}$ J. Wöllenstein, M. Burgmair, G. Plescher, T. Sulima, J. Hildenbrand, H. Böttner, and I. Eisele, Sens. Actuators, B 93, 442 (2003).

${ }^{8}$ M. M. Natile and A. Glisenti, Chem. Mater. 14, 3090 (2002).

${ }^{9}$ H. Sun, H. M. Ang, M. O. Tadé, and S. Wang, J. Mater. Chem. A 1, 14427 (2013).

${ }^{10}$ X. Xie, Y. Li, Z.-Q. Liu, M. Haruta, and W. Shen, Nature 458, 746 (2009).

${ }^{11}$ F. Jiao and H. Frei, Angew. Chem. 48, 1841 (2009).

${ }^{12}$ A. Agiral, H. S. Soo, and H. Frei, Chem. Mater. 25, 2264 (2013). 
${ }^{13}$ Y. Liang, Y. Li, H. Wang, J. Zhou, J. Wang, T. Regier, and H. Dai, Nature Mater. 10, 780 (2011).

${ }^{14}$ T. Q. Ngo, A. Posadas, H. Seo, S. Hoang, M. D. McDaniel, D. Utess, D. H. Triyoso, C. Buddie Mullins, A. A. Demkov, and J. G. Ekerdt, J. Appl. Phys. 114, 084901 (2013).

${ }^{15}$ S. C. Petitto and M. A. Langell, J. Vac. Sci. Technol. A 22, 1690 (2004).

${ }^{16}$ Z.-X. Shen, J. W. Allen, P. A. P. Lindberg, D. S. Dessau, B. O. Wells, A. Borg, W. Ellis, J. S. Kang, S.-J. Oh, I. Lindau, and W. E. Spicer, Phys. Rev. B 42, 1817 (1990).

${ }^{17}$ M. A. Langell, M. D. Anderson, G. A. Carson, L. Peng, and S. Smith, Phys. Rev. B 59, 4791 (1999).

${ }^{18}$ L. Qiao, H. Y. Xiao, H. M. Meyer, J. N. Sun, C. M. Rouleau, A. A. Puretzky, D. B. Geohegan, I. N. Ivanov, M. Yoon, W. J. Weber, and M. D. Biegalski, J. Mater. Chem. C 1, 4628 (2013).

${ }^{19}$ K. J. Kim and Y. R. Park, Solid State Commun. 127, 25 (2003).

${ }^{20}$ H. Shirai, Y. Morioka, and I. Nakagawa, J. Phys. Soc. Jpn. 51, 592 (1982).

${ }^{21}$ G. N. Maslennikova, Glass Ceram. 58, 216 (2001).

${ }^{22}$ M. Bouchard and A. Gambardella, J. Raman Spectrosc. 41, 1477 (2010).

${ }^{23}$ W. L. Roth, J. Phys. Chem. Solids 25, 1 (1964).

${ }^{24}$ P. Dutta, M. S. Seehra, S. Thota, and J. Kumar, J. Phys.: Condens. Matter 20, 015218 (2008).

${ }^{25}$ T. Mousavand, T. Naka, K. Sato, S. Ohara, M. Umetsu, S. Takami, T. Nakane, A. Matsushita, and T. Adschiri, Phys. Rev. B 79, 144411 (2009).

${ }^{26}$ H. Yoshikawa, K. Hayashida, Y. Kozuka, A. Horiguchi, K. Awaga, S. Bandow, and S. Iijima, Appl. Phys. Lett. 85, 5287 (2004).

${ }^{27}$ C. Noguera, J. Phys.: Condens. Matter 12, R367 (2000).

${ }^{28}$ U. Diebold, S.-C. Li, and M. Schmid, Annu. Rev. Phys. Chem. 61, 129 (2010).

${ }^{29}$ H. Y. Hwang, Y. Iwasa, M. Kawasaki, B. Keimer, N. Nagaosa, and Y. Tokura, Nature Mater. 11, 103 (2012).

${ }^{30}$ Y. Z. Chen, N. Bovet, F. Trier, D. V. Christensen, F. M. Qu, N. H. Andersen, T. Kasama, W. Zhang, R. Giraud, J. Dufouleur, T. S. Jespersen, J. R. Sun, A. Smith, J. Nygård, L. Lu, B. Büchner, B. G. Shen, S. Linderoth, and N. Pryds, Nat. Commun. 4, 1371 (2013).

${ }^{31}$ W. Meyer, K. Biedermann, M. Gubo, L. Hammer, and K. Heinz, J. Phys.: Condens. Matter 20, 265011 (2008).

${ }^{32}$ K. B. Klepper, O. Nilsen, and H. Fjellvåg, Thin Solid Films 515, 7772 (2007).

${ }^{33}$ M. E. Donders, H. C. M. Knoops, M. C. M. Van, W. M. M. Kessels, and P. H. L. Notten, J. Electrochem. Soc. 158, G92 (2011).

${ }^{34}$ K. B. B. Klepper, O. Nilsen, and H. Fjellvåg, J. Cryst. Growth 307, 457 (2007).

${ }^{35}$ K. Shalini, A. U. Mane, S. A. Shivashankar, M. Rajeswari, and S. Choopun, J. Cryst. Growth 231, 242 (2001).
${ }^{36}$ D. Barreca, A. Devi, R. A. Fischer, D. Bekermann, A. Gasparotto, M. Gavagnin, C. Maccato, E. Tondello, E. Bontempi, L. E. Depero, and C. Sada, CrystEngComm 13, 3670 (2011).

${ }^{37}$ E. Fujii, H. Torii, A. Tomozawa, R. Takayama, and T. Hirao, J. Mater. Sci. 30, 6013 (1995)

${ }^{38}$ A. U. Mane, K. Shalini, and A. Wohlfart, J. Cryst. Growth 240, 157 (2002).

${ }^{39}$ R. J. Kennedy, IEEE Trans. Magn. 31, 3829 (1995).

${ }^{40}$ C. A. F. Vaz, D. Prabhakaran, E. I. Altman, and V. E. Henrich, Phys. Rev. B 80, 155457 (2009).

${ }^{41}$ C. A. F. Vaz, H.-Q. Wang, C. H. Ahn, V. E. Henrich, M. Z. Baykara, T. C. Schwendemann, N. Pilet, B. J. Albers, U. D. Schwarz, L. H. Zhang, Y. Zhu, J. Wang, and E. I. Altman, Surf. Sci. 603, 291 (2009).

${ }^{42}$ C. A. F. Vaz, E. I. Altman, and V. E. Henrich, Phys. Rev. B 81, 104428 (2010).

${ }^{43}$ C. J. Zollner, T. I. Willett-Gies, S. Zollner, and S. Choi, "Infrared to vacuum-ultraviolet ellipsometry studies of spinel $\left(\mathrm{MgAl}_{2} \mathrm{O}_{4}\right)$," Thin Solid Films (published online).

${ }^{44}$ H. G. Tompkins and W. A. McGahan, Spectroscopic Ellipsometry and Reflectometry: A User's Guide (Wiley, New York, 1999).

${ }^{45}$ H. Fujiwara, Spectroscopic Ellipsometry (Wiley, Chichester, UK, 2007).

${ }^{46}$ H. Zheng, M. Gruyters, E. Pehlke, and R. Berndt, Phys. Rev. Lett. 111, 86101 (2013).

${ }^{47}$ S. A. Chambers, T. Ohsawa, C. M. Wang, I. Lyubinetsky, and J. E. Jaffe, Surf. Sci. 603, 771 (2009).

${ }^{48}$ R. C. Hatch and H. Höchst, Surf. Sci. 604, 1684 (2010).

${ }^{49}$ S. A. Chambers, Y. Liang, Z. Yu, R. Droopad, J. Ramdani, and K. Eisenbeiser, Appl. Phys. Lett. 77, 1662 (2000).

${ }^{50}$ X.-L. Xu, Z.-H. Chen, Y. Li, W.-K. Chen, and J.-Q. Li, Surf. Sci. 603, 653 (2009).

${ }^{51}$ J. Chen, X. Wu, and A. Selloni, Phys. Rev. B 83, 245204 (2011).

${ }^{52}$ J. Chen and A. Selloni, Phys. Rev. B 85, 085306 (2012).

${ }^{53}$ J. C. Green and P. Decleva, Coord. Chem. Rev. 249, 209 (2005).

${ }^{54}$ M. Lenglet and C. K. Jørgensen, Chem. Phys. Lett. 229, 616 (1994).

${ }^{55}$ E. M. Marsh, S. C. Petitto, G. S. Harbison, K. W. Wulser, and M. A. Langell, J. Vac. Sci. Technol. A 23, 1061 (2005).

${ }^{56}$ M. Khalid, A. Setzer, M. Ziese, P. Esquinazi, D. Spemann, A. Pöppl, and E. Goering, Phys. Rev. B 81, 214414 (2010).

${ }^{57}$ D. Bloch, J. Phys. Chem. Solids 27, 881 (1966).

${ }^{58}$ Y. Ikedo, J. Sugiyama, H. Nozaki, K. Mukai, H. Itahara, P. L. Russo, D. Andreica, and A. Amato, Physica B 404, 652 (2009).

${ }^{59}$ See supplementary material at http://dx.doi.org/10.1063/1.4885048 for optical constants (real and imaginary part of the dielectric function) of $\mathrm{Co}_{3} \mathrm{O}_{4}$ as a function of photon energy determined using spectroscopic ellipsometry. See Fig. 9 for a graphical representation of these optical constants. 